reall now four cases where I patiently rubbed the eye from within outward with the ball of the second finger, as directed, for one-half hour daily for weeks. Of these cases, one of traumatic eataract showed not the slightest change. Another, of congenital eataract, undertaken at his earnest request, whowed not the slightest change at the time nor several years later. Two other cases of senile cataract resulted as follows: One became more rapidly progressive than I have noticed in other patients of the same age, and the other remained stationary until the time of the patient's death. I now tell my patients with senile cataract, keep your digestion good, use your eyes reasonably, do not worry.

DR. G. E. DE SChwervitz, closing-Opacities in the nasal quadrant are sometimes nearly non-progressive, that is, their progress is certainly very slow. There is another variety that is associated with a corresponding patch of retino-choroiditis that does progress. My only object in bringing up this subject was that we should discuss the hest measures for the relief of these patients, and to state my belief, which has been strengthened by the discussion, that there is some reason to believe that we can help these people with proper treatment.

\section{RHEUMATISM AND THE PREVENTION OF HEART COMPLICATIONS.*}

JAMES J. WALSH, M.D., Pri.D.

\author{
Instructor in Diseases of the Chest and General Medicine, New \\ York Polyclinic. \\ NEW YORK CITY.
}

Hore than fifteen years ago Eichhorst, of Zurich, in the third edition of his "Handbuch der Speciellen Pathologie und 'Therapie," transferred rheumatism from the class of constitutional to that of infectious diseases. In doing so he was only expressing a conviction that had been forming among clinicians generally. Because of certain superficial resemblances to gout, rheumatism had been classed among diathetic diseases, but without good reason, as time and closer clinical observation showed. Eichhorst's position was not unique, but it is only after fifteen years that the medical profession is coming to acknowledge its correctness. We have at length come to the point of conceding the infectious nature of rheumatism. The reasons given by Eichhorst before any germs had been described as occurring in the lesions of the disease are to-day the best arguments for its infectiousness. Rheumatism has all of the characteristics of an acute infectious fever-the incubation period, the sudden rise of temperature and the remission, with gradual convalescence. It occurs particularly in damp weather, but so does pneumonia, and the dampness seems to stand only in a secondary causal relation to the disease. Even its contagiousness, under certain circumstances, is well established. It has been known to spread through a hospital ward, and to frequently attack several members of a family at the same time. In schools and barracks single cases of it are rarer than the occurrence of several about the same time. According to Eichhorst, Pocock, Schaefer, Jaccoud and von Striimpell. pregnant women have been seen suffering from rheumatism who gave birth to children presenting the symptoms of acute rhermatism.

'The infectious nature of the disease is shown by its tendency to produce lesions in the most widely different parts of the body. An acute rheumatic arthritis of the wrist or ankle may be complicated by a rheumatic menincitis, endocarditis, or pleuritis. Autopsies made on pationts dead during the acute stage of the disease present striking indications of an infectious disease. Hem-

* Presented to the Section on Practice of Medicine, at the Fiftyfirst Annual Meeting of the American Medical Association, held at Atlantic City, N. J.. June 5-8, 1900. orrhages into the various organs are noted; there is cloudy swelling of the cells, of the heart, of the kidneys, and of the liver. There is the enlarged spleen of distinctly lessened consistency so characteristic of infectious diseases.

\section{BACTERIOLOGY.}

Notwithstanding that rheumatism seems to be an infectious disease, no definite bacterial cause has as yet been established. As long ago as 1883 Babes found bacilli and cocci in the synorial fluid of a patient who died during the course of an acute rheumatism from intercurrent nephritis. Observers have found other microorganisms in various fluids of rheumatic patients who had succumbed to some complication. All of these were isolated observations until the beginning of the present decade, when Bouchard and Charrin found various forms of staphylococci in six different cases in the synovial fluid of patients suffering from rheumatism. ShortIy afterward Achalme found an anaerobic bacillus in the tissues of two cases. A third case of the same kind was noted the next year. Other investigators failed in a number of cases to find the micro-organism described by Achalme, though one or two confirmed his results. Triboulet and Coyon found a series of micro-organisms in rheurnatic patients, occasionally staphylococci, sometimes streptococci, in rare cases Achalme's bacillus, and almost constantly a diplococcus. In eleven consecutive cases of acute articular rheumatism that came under thoir observation in succession, some of them severe, others comparatively mild, this diplococcus was found. Cultures made from the blood always resulted in the growth of this germ, which they consider the cause of rheumatism. Intravenous injection of this diplococcus into animals always causes endocarditis of the left side of the heart, especially of the mitral valve. German obserrers, as a rule, have not found micro-organisms in the blood or in the secretions. Singer, it is true, found various micro-organisms in the synovial fluid in the blood and in the urine of patients suffering from rheumatism, but only in a small proportion of cases. His results were not substantiated by Chvostek, who is a careful observer. The blood in all of sixteen cases examined by Chyostek was uniformly sterile; only once was the articular fluid removed from rheumatic joints found to contain bacteria. These proved to be bacilli, but scant in number. Some years ago Leyden and the assistants in his clinic found a diplococcus in rheumatism; Senator found a streptococcus. The only microorganism which may be considered to have sufficient evidence in its faror to justify its being considered as a frequent cause of rhemratism is the diplococcus form. Eren this, however, has not been found often enough to justify any definite conclusion as to its specific pathogeneity.

\section{RIIEUALTTSII NO'I A SIMPLE DISEASE ENTITY.}

Several important deductions may be made from the multiplicity of the micro-organisms that have been found by different observers. It is clear, even from clinical observation, that acute articular rheumatism as we know it is not a simple nosological entity, but is probably a series of similar diseases more or less closely related to one another. The term "pnewmonia" a quarter of a century ago embraced a number of affections that we can now easily differentiate from each other. The ordinary self-limited acute arthritis, which usually terminates of itself in from ten to fourteen days, is perhaps due to the diplococcus found so often. Cases that run a longer course. and prove intractable, are duc to other forms of bacterial life, or are complicated $\mathrm{hr}$ 
secondary infection. The rapidly fatal cases of rheumatism with high temperature, coma and collapse, of which quite a few have been reported by various obserrers, are probably due to the anaterobic bacillus clescribed by Achalme.

\section{TIIE ACID IDLTLESIS IN RHEUMATISM.}

If we are to accept rheumatism as an infectious disease with a bacterial cause, the question arises, has the acid diathesis, which meant so much for a preceding generation, in the production of rheumatism, no effect in the etiology of the disease? 'There are those who, like Haig in England, still insist that the urie-acid diathesis is the constitutional basis of all rheumatic manifestations. This view has long been abandoned by most of the profession. For many of the older practitioners lactic acid is still supposed to play an important rôle in the calusation of rhemmatism. It is hard to understand on what the comviction of the etiologic importance of lactic aciol is based. The feeding of lactic acid to animals does produce joint lesions, but very different from those of acnte arthritis. Lactic acid has been used in considerable quantities in recent years as a remedy for diabetes, but it has never been known especially to predispose diabetics to arthritic manifestations.

'The idea of an acid diathesis in rhemmatism seems to be founded on a series of misconceptions. The urine of rheumatism is sajd to be acid. Yet there are those is the urine of any febrile condition. The perspiration of rheumatism is said to be acid. Tet there are those who say that it is alkaline when recently exuded, and only acid after standing. There are others who insist that it is oricinally acid. The only solution of the question seems to be that sometimes the sweat of rheumatism is acid and sometimes it is neutral or alkaline.

It seems interesting to note that if the blood in rheumatism is acid, as it is said to be by many, it would prove a much less farorable culture-medium for microorganisins than when in its normal condition. Most of the ordinary progenic cocci either do not grow on an acid culture-medium, or grow much less luxuriantly and with lessened virulence. It is possible, then, that the hyperacidity of the blood is a protective reaction on the part of nature. The reason why pyogenic cocci in the circulation do not produce pyemia is perhaps because their growth is inhibited in numbers and in vitality by the acid medium in which they are. The alkali treatment as ordinarily given in rheumatism would then be a simple undoing of nature's protective process. As there are many who seem to doubt that the alkali treatment does any good, this makes the question of its employment rather serious.

\section{SELF-LLMITATION AND LOW MORTALITY.}

Next to its being an infectious disease, the most important thing about rheumatism is that it is self-limited. 'This feature has been as much overlooked as its infectious origin. To Austin Flint, according to Professor Osler, belongs the credit of having first pointed this out. Notwithstanding the many remedies recommended for its treatment, rheumatism, like the other infectious diseases, remains practically uninfluenced in its course by any remedy. Symptoms, especially the pain and the fever, may be very much alleviated, but the duration is probably very little, if at all, affected by any treatment.

Rheumatism is a disease which is very seldom fatal. Professor Pribram, of Prag. has had under his care in the last sixteen vears $62 \%$ cases. Of these, but six proved fatal; only one from hyperpyrexia. This was the only case in which the complication that brought about death could with any assurance be attributed to the rheumatism itself. Of the five other cases, one died from tuberculosis of the lungs, two from nephritis and uremia, one from pneumonia, and one from sepsis including osteomyelitis and metastatic abscesses. 'The mortality of the discase itself is probably not more than 1 per cent.

\section{IIEART COMPLICATIONS.}

Profesor Osler thinks that the number of heart complications in rheumatism is grossly exaggerated. In 209 cases carefully examined for this purpose he found only : t endocardial involvements, while French writers give as high as 65 per eent. Vernal, as the result of serural luundred observations, gives the percentage in the rheumatism of children as more than 80 per cent.; Church, 6i per eent. in cases between 10 and 20 years of age, and 5 t per cent. between the ages of 20 and 30 years. Hirsch found 52 per eent. between the ages of 16 and 20,65 per cent. between 21 and 25,50 yer cent. between 26 and 30 , and 83 per cent. between 31 and 35 . Pribran, to whom I owe these figures, and whose monograph on acute rheumatism in Tothnagel's "Specielle Pathologie und Therapie" shows how thorouglny he has reviewed the literature of the subject, besides havine a very practical acquaintance with the affection clinically, gives the average number of heart complication: in primary attacks of acute rheumatism as from 38 to 40 per cent. In this he includes about 5 per eent. of pericardial complications.

How often chronic endocarditis is due to rheumatism is quite as interesting a question, and perhaps cren more important. The statisties as to the rheumatic origin of chronic endocarditis are quite as indefinite in their way as those of percentage of heart complications that occus from rheumatism. Once more the French authorities give the highest numbers. Seventy per cent. of all cases of endocarditis are said to be due to rheuma. tism. All infectious fevers may cause endocardial involrement. In taking the history of a patient with a heart lesion, we all realize, especially in recent years. how important it is to consider rheumatism.

\section{TREATMEN' $\mathrm{T}$}

At the end of the last century, to a student who asked what was the best thing for rheumatism, Corrigan, the distinguished Irish surgeon, said, "Six weeks." During the first half of the century the medical profession, in England particularly, believed very firmly in the efficacy of the alkali treatment. About 1860 the coal-tar colors were found, and among other members of the coal-tar derivative group was salicylic acid, which proved on trial to have a remarkable effect in alleviating the symptoms of rheumatism. Something that is not generally remembered, however, is that an extract of the willow tree had been in use in Fngland for nearly a century as a useful remedy for rheumatism. About the time that salicylic acid became so popular in Germany, salicin acquired a reputation in England.

It is the custom to say that the course of rheumatism has been very much shortened and all of its symptoms alleviated much sooner by treatment with the salicylates than by any treatment employed before the introduction of salicylic acid and its derivatives into therapentics. There is a very interesting table that presents the facts concerning the influence of salicylic acid and its derivatives on rheumatism as they were observed during eight years at the city hospital in Berlin. For alternate periods varying between half a year and a year and a quarter the salicylate treatment and so-called indif- 
ferent treatment were employed in all cases of rheumatism. The alternations from one method of treatment to the other were made deliberately with the idea of counteracting any influence that the season of the year or the special epidemic virulence of rheumatism at any period might have in making cases of the disease more intractable or more persistent. Altogether, 148 cases were treated with the salicylates and 106 with indifferent remedies; that is, iodid of potassium and the alkalies, with whatever other drugs might seem to be indicated by the symptoms.

\begin{tabular}{|c|c|c|}
\hline & $\begin{array}{c}\text { Salicylates. } \\
\text { Days. }\end{array}$ & $\begin{array}{c}\text { Indifferent } \\
\text { Treatment } \\
\text { Days. }\end{array}$ \\
\hline 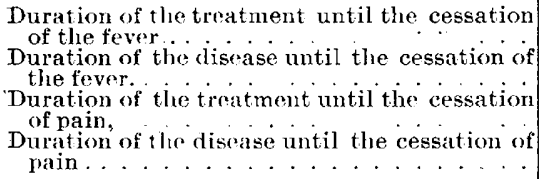 & $\begin{array}{r}4.2 \\
11.6 \\
8.7 \\
16.4\end{array}$ & $\begin{array}{r}6.5 \\
15.0 \\
9.3 \\
18.0\end{array}$ \\
\hline
\end{tabular}

Retapses, under salicylates, 31.3 per cent, under indifferent treatment. 13.2 per cent.

Heart complications, under salicylates, 17.6 per cent ; under indifferent treatment, 16.4 per cent.

Length of stay in the hospital, under salicrlates. 36. days; under indifferent trat.ment, 34.5 days.

As the mortality is practically nil, the important consideration is the avoidance of heart complications. This salicylis acid was said to do very effectually. Experience, however, has not justified this claim. The general evidence of the English collective investigation committee, as quoted by Cheadle, is that cardiac complications are less frequent and less pronounced under full alkaline treatment than by any other method. Pribram says that, while salicylic acid is the best remedy for the relief of the symptoms of rheumatism, it neither shortens the course of the disease nor lessens the number and severity of the heart complications.

Salicylic acid received its reputation in Germany, hence it is interesting to note the present situation there. It was in Senator's clinic that the original work with the drug was done, yet Senator himself said, two years ago, that salicylic acid is not a specific for rheumatism, but that it does relieve the symptoms, lessen the pain and lower the fever. Other coal-tar products, however, accomplish this purpose, and it is only that salicylic acid seems to be less objectionable than other antipyretic analgesics that it is to be preferred.

In Leyden's clinic at the Charite the routine treatment of rheumatism is with antipyrin. Four to six grams are given on the day that the patient enters the hospital and the same amount repeated the next day. This usually does away with fever and pain completely. Then a gram and a half to two grams are given each day for some weeks. Gerhardt occupies a middle position between Leyden and Senator. He thinks that any of the coal-tar antipyretics should be used, but prefers phenacetin. If this fails to relieve the symptoms, antipyrin is given, or one of the salicylates.

This would seem an unsuitable treatment here, where a strong prejudice exists against the use of antipyrin. 'To administer it in rheumatism where heart complications are feared would seem foolish. Leyden and Gerhardt, both heart specialists, are convinced that antipyrin, far from increasing the liability to heart complieations rather diminishes it. It lowers the temperature and the pain, and so brings down the pulse-rate. Anything that reduces the work the heart has to do lessens the tendency to the production of heart lesions. There are undoubtedly cases in which antipyrin acts as a serious depressant to the heart and the circulation. Notwithstanding very alarming symptoms, deaths from the drug are very few. The occurrence of symptoms seems to be due not to the amount of the drug ingested, but to an idiosyncrasy for it.

I would not, however, be considered as an advocate of the antipyrin treatment of rheumatism. I wish merely to insist that we have not in the salicylates a specific, but only a remedy that relieves pain and fever. Almost any other of the antipyretics will do this quite as effectually.

It is probable that none of the antipyretics have eventually done good in the treatment of rheumatism. The relief of symptoms has allowed patients to get up and be around much sooner than would be the case if the disease ran its course undisturbed by antipyretics or analgesies. In England, particularly, a number of prominent clinicians insist that relapses are more frequent after the salicylic treatment of rheumatism and that the heart complications, instead of being less, are at least as frequent, and probably more severe.

Rest is the most important indication for the heart complications. The heart of a normal person walking is ten beats faster per minute than if he is lying down, which means one-seventh more work. Maclagen says that in England only one-half as many heart complications are noted in rheumatic cases that have been in bec? from the beginning of the attack as in those who have been up and around for some time. There is an old prejudice, and a most unfortunate one, that will-power may enable one to throw off disease, or at least to diminish its severity.

The treatment for rheumatism is rest, not alone during the active stage of the disease, but for weeks afterward if there has been any heart complication. The old indifferent treatment is a precious heritage which is uniformly too much neglected. There is no doubt that the deposit on the valves of the heart may in its early and plastic stage be much influenced by the resorbent properties of the iodids. Its careful ad. ministration for weeks after an attack of acute rheumatism, while the patient is kept absolutely in bed, would do more to reduce the mortality from heart disease, which is so striking a feature of modern life, than all the vaunted specifics that the manufacturing chemists turn out. Since the public generally have come to realize the value of the antipyretics in the treatment of painful conditions of any kind, many of the milder cases of rheumatism run their course without professional assistance. The result is the development of many an unsuspected heart lesion for which a few years afterward it is extremely difficult to find an adequate reason.

"Prevention of Heart Complications." This is the favorite slogan of the advocates of each new remedy and newest method of treating rheumatism. If it could be accomplished, rheumatism would be much less to be feared than any infectious disease we have. It would be a painful episode in life and nothing more. As a matter of fact, however, no method of treatment so far introduced seems to have any influence in limiting either the number or the severity of heart complications. It is doubtful even if the endocarditis and pericarditis which develop in the course of rheumatism are really a complication. There are undoubtedly cases in which either rheumatic endocarditis or pericarditis occurs and runs its course without accompanying arthritic lesions. When rheumatism appears in one joint, there is no method of treatment which gives any assurance of pre- 
venting it affecting other joints. The heart and its serous coverings occupy a corresponding place in rheumatism to that of the joints. It is interesting to note that the rheumatic affection always appears on a particular side of the valves of the heart and is limited to the left heart. The rheumatic process always begins at the point where the valve leaflets touch one another, on the auricular side of the mitral valve, on the ventricular side of the aortic valve. When it appears on the ventricular endocardium it is at points where the valves touch it when they are drawn back. The rheumatic process in the joints occurs in serous surfaces that are also in contact with one another. It is only on the contact points, the joints of the heart, so to say, that the so-called rheumatic complication occurs. Rheumatism in the heart is really not a complication, but is as much of the essence of the disease as is its occurrence at contact points on the serous surfaces of the joints. Until we can get some remedy which will control rheumatism and prevent its spread from joint to joint, or act as a prophylactic against the development of the disease as soon as its preliminary symptoms are manifest, we can scarcely hope to prevent rheumatic heart complications.

\section{THE HEART IN ACUTE RHEUMATISM.*}

DET,ANCEY ROCHESTER, A.B., M.D.

Associate Professor of Principles and Practice of Medicine. University of Buffalo; Consulting Physician, German Deacones

Hospital : Attending Physician, Erie County Hospital Attending Physician, Buffalo Hospital of Sisters of Attending Physician, Buffalo Fospital of Sisters Charity; Assistant Attending Phy

BUFFALO, N. Y.

As long ago as 18\%0, Sir Thomas Watson, in his wonderfully clear lectures, one of the greatest works on medicine published, says: "In truth, acute rheumatism is a blood disease. The circulating blood carries with it a poisonous material, which by virtue of some mutual or elective affinity, falls upon the fibrous tissues in particular, visiting them and quitting them with a variableness that resembles caprice, but is ruled, no doubt, by definite laws, to use, as yet, unknown."

In our actual knowledge of the materies morbi of this particular disease we have made no material advance in the last thirty years. Flint, in 1881, said: "A special predisposition is requisite; in other words, the disease involves a rheumatic diathesis. This predisposition may be congenital and inherited, or it may be acquired. Statistics establish conclusively the hereditary transmission of the disease. When we recall, however, that at that time statistics also "established conclusively the hereditary transmission" of tuberculosis and that in the light of modern science these conclusions have been shown to be erroneous, we are justified in doubting the "conclusive establishment of the hereditary transmission of rheumatism."

Lyman, in Pepper's "System," says: "Hereditary causes exert an important influence upon the occurrence of articular rheumatism-so far as statistics have been collected, it seems probable that from one-quarter to one-third of those afflicted are the descendants of rheumatic ancestors." "The same author says: "The question of an infective cause for acute rheumatism has not been decided. Many of the symptoms of the disease and its mode of prevalence seem to be indicative of an infective cause. There is, however, no satisfactory

* Presented to the Section on Practice of Medicine. at the Niftyheld at Atlantic City, N. J., June 5-8, 1900. evidence of the transmissibility of the disease from one person to another, nor has any infective micro-organism been discovered that can excite symptoms of rheumatism."

In Allbutt's system, Dr. Church, in the article on acute rheumatism, says: "Although no satisfactory evidence has as yet been procured of the constant presence of any single specific micro-organism, yet in not a few of its features the whole course of rheumatic fever resembles an infective disease." In the course of his review of the etiology of acute rheumatism, Osler says: "In the character of the fever, the mode of involvement of the joints, the tendency to relapse, the sweats, the anemia, the leucocytosis and, above all, the great liability to endocarditis and involvement of the serous membranes, acute rheumatic fever resembles premia very closely and may, indeed, be taken as the very type of an acute infection."

After a careful study of the various hypotheses as to the nature and cause of acute rheumatism, MacLagan, in the "Twentieth Century Practice," says: "It is in connection with the pathogenesis of rheumatic fever that we have been led to consider the nature and mode of action of malaria. We believe the rheumatic poison to be malarial in nature. If it be so, it is a minute parasitic organism whose morbific action, like that of other malarial poisons, is dependent on its growth and reproduction in the system."

Thus we see from this brief review that the trend of opinion is toward the infectious nature of the disease, as Packard says, in his résumé of the subject, in Progressive Medicine, for March, 1900: "Rheumatism is a disease produced by external agencies. While in many instances it seems to result from exposure to cold or wet, alone or in combination, there is no way by which we can explain the action of these factors, except by their lowering the vitality and permitting the invasion of the body as is held to be the case with other well-known infections." Of the specific infectious nature of acute rheumatism the writer has no doubt. One of the peculiarities of this infection is that it invades the heart, and particularly the valves of the heart, with much greater frequency than any of the other acute infections, with the possible exception of chorea and pyemia. The possible etiological relation of these three diseases is most interesting. but it it not my function to discuss it.

As to the frequency with which morbid changes occur in the heart in association with acute rheumatism, a review of the literature of the subject, together with my own experience, brings me to the conclusion that cndocarditis occurs in fully 60 per cent. of the cases, pericarditis occurs in about 10 per cent. Statistics and observations as to the occurrence of myocarditis are lacking and must always be a subject of doubt, as the data of its occurrence are dependent almost entirely on clinical observations, as so few cases of acute rheumatism come to autopsy during the acute stage and the mrocardial changes associated with old endoeardial deformities may be dependent on so many other concomitant causes as to be thrown out of consideration. Moreover, the recognition of myocarditis during life is exceedingly difficult. Nevertheless, it is the opinion of the writer that myocarditis occurs in conjunction with all cases of pericarditis and in conjunction with many cases of endocarditis, is present in not a few cases where neither endocarditis or pericarditis is present, and sometimes is wrongly diagnosed as endocarditis. 